\title{
Effect of Language Switching On the Response Latency in the Cued Picture-Naming Paradigm among Hindi Dominant and Balanced Bilinguals
}

\author{
Mishra K. A. ${ }^{1}$, Asthana, H. S. ${ }^{2}$, Singh, I. L. ${ }^{2}$
}

\section{ABSTRACT}

Language dominance has long been considered an important factor in determining the processing time associated with language switching. It is evident that when an unbalanced bilingual switch from ones non-dominant to dominant language (backward switching), s/he requires more reaction time in comparison to when s/he switches from dominant language to non-dominant language (forward switching). In this study, the researcher examined the effects of language dominance and switching on the response time in the cued picture-naming paradigm. Results indicate that the overall response time required by balanced bilingual is less than that of Hindi dominant bilinguals. It was also found that, Hindi dominant required more reaction time in backward switching in comparison to forward switching. For balanced bilinguals, the difference between forward and backward switching was not found to be significant. The results of this study have been discussed in light of the concept of 'reactive inhibition' of the Inhibitory Control Model (ICM).

Keywords: Language switching, Language dominance, Inhibitory Control Model (ICM), Response latency.

Until recently, the understanding of the representations and the use of a single language was investigated in research. However, due to the increasing multilingual presence everywhere the interest in bilingualism has grown tremendously. Furthermore, the awareness that research on bilingualism provides methods to uncover constraints within the cognitive architecture of bilinguals drew attention to this research field. Consequently, there has been an enormous increase in the activity within this field.

The representation of two languages in a bilingual's mind should make lexical selection more difficult than for monolinguals (French \& Jacquet, 2004). General cognitive studies with

\footnotetext{
${ }^{1}$ Ph.D. Scholar, Department of Psychology, Banaras Hindu University, Varanasi, U.P., India

${ }^{2}$ Professor, Department of Psychology, Banaras Hindu University, Varanasi, U.P., India

*Responding Author (c) 2016 I K Mishra, H Asthana, I Singh; licensee IJIP. This is an Open Access Research distributed under the terms of the Creative Commons Attribution License (http://creativecommons.org/licenses/by/2.0), which permits unrestricted use, distribution, and reproduction in any Medium, provided the original work is properly cited.
} 


\section{Effect of Language Switching On the Response Latency in the Cued Picture-Naming Paradigm among Hindi Dominant and Balanced Bilinguals}

bilinguals showed that bilinguals' ability to ignore irrelevant stimuli and select goal-relevant information is enhanced. Bilinguals seem to have cognitive advantages compared to monolinguals as bilinguals need to pursue a stronger maintenance of goals in their working memory (Colzato et al., 2008). Researchers explained these discoveries by the circumstance that bilinguals constantly needed to keep two languages separated (Hernandez, Dapretto, Mazziotta, \& Bookheimer, 2001). In order to use one language, the other one must somehow be 'neglected'.

In the past years, there has been a lot of research in order to explore the mechanism that enables bilinguals to restrict their lexicalization process to only one language. In order to do so, researchers concentrated on conducting studies in which bilinguals were asked to switch between two languages. These studies made use of production (or comprehension) tasks, which required the participants to name (or press the corresponding button) the digits, pictures, or other stimuli in their first / mother / native language (L1) or second / foreign / non-native language (L2). There are different trials in a language-switching study that can either be defined as non-switch trials or switch trials. In non-switch trials the response language remains the same within two consecutive trials whereas in switch trials the response language alters from the previous to the current trial. Even though this might seem to be smooth to the listener, there will likely be a time cost associated with it. The difference between Response times in switch and non-switch trials in each language is referred to as switch costs (Meuter \& Allport, 1999). For example, the bilingual requires approximately 600 milliseconds to make a response on the switch trials and 530 milliseconds on the non-switch trials; the difference of 70 milliseconds is regarded as the switch cost pertaining to moving from one language to the other. This cost has been observed in language production (Costa \& Santesteban, 2004) and in comprehension (Thomas \& Allport, 2000).

\section{THE INHIBITORY CONTROL MODEL:}

The Inhibitory Control Model (ICM) is a very influential model by Green (1998).

Green (1998) assumes that there is cross-language activity and that languages compete for selection. The basic idea of the model is that the selection of one language can only be supported by inhibiting the non-target language. Accordingly, in a language-switch situation, the effects of prior inhibition have to be overcome to select the target language. Besides that, those language lemmas of the non-target language that were previously active have to be inhibited now. The process of overcoming inhibition takes time and results in longer RTs and more errors (i.e. switch costs) than when a person uses the same language again. Therefore, Green (1998) defined switch costs as an empirical marker for inhibition.

Macnamara (1967) speculated that, since L1 is dominant language, thus it should be easier to speak and also the easier language to switch to. However, this dominance-driven intuition is only partly accurate as Meuter \& Allport (1999) demonstrated that switching to the dominant L1 is 


\section{Effect of Language Switching On the Response Latency in the Cued Picture-Naming Paradigm among Hindi Dominant and Balanced Bilinguals}

measurably more difficult than switching to the less dominant L2 in non balanced bilinguals, while the repeated same-language responses showed the expected pattern of language dominance. This phenomenon is what Green (1998) interpreted as 'inhibition is reactive' which means that the strength of inhibition is dependent on the strength of activation. It means that the language that is more activated needs stronger inhibition in order to select the weaker language. When speaking L1, little inhibition is required for the less dominant L2 because the baseline level of activation of L2 lexical items are lower than that of L1 lexical items. However, whenever speaking lexical items in L2 the L1 representations must be sturdily inhibited in order to ensure that $\mathrm{L} 2$ lexical items are selected.

Consequently, asymmetrical switch costs are predicted to arise in language switching studies. Asymmetrical switch costs are a combination of slower response latencies in the more dominant language and faster response latencies in the less dominant language in switch trials. In a German (L1) / English (L2) switch task, participants usually respond faster in German if there is no switch. But in a switch trial, the L1 is more inhibited than the L2 since L1 is more dominant (Meuter, 2005). Therefore, it should be easier to switch into the less dominant language due to reactive inhibition than to switch into the dominant language. It is further speculated that, constant switching between languages should lead to similar dominance of both languages (as in the case of balanced bilinguals). That is, when a person has to switch between L1 and L2 very often, L2 should be improved automatically as it is used frequently. Consequently, the dominance difference between L1 and L2 is reduced. According to Green (1998) this should result in less asymmetry and possibly smaller switch costs than when the dominance of the two languages is very different.

The literature suggests that the language processing in bilinguals is explained well through the Green's (1998) Inhibitory Control Model, but there is still a controversy regarding the switch cost pattern which is evident in switch trials. A study by Gollan and Ferreira (2009) indicates that despite huge processing cost during switch trials, there was symmetrical switch cost across languages. On the contrary, most other researchers have shown that when the bilingual switches from his / her non-native to native language, they require more response time in comparison to when they switch from their native to non-native language, i.e., the switch cost was asymmetrical (Green, 1998; Meuter \& Allport, 1999; Meuter, 2005). Thus we can find that dominance driven intuition is challenged in some instances.

We can even find that in the previous studies, while assessing the language dominance emphasis was laid only on the self-rated proficiency in the reading, writing, speaking and comprehending ability of the bilinguals. Other factors like frequency of usage and level of confidence in the handling of the specific language were ignored. These factors are assumed to have a latent impact on the overall language proficiency and in turn may vary the language dominance. We can even find that in most of the previous studies, certain methodological refinements are 
possible. Taking these things into account the present study was planned, and objectives were framed. Based on the major objective, the following hypotheses were framed,

1. Balanced bilinguals would be faster than Hindi dominant bilinguals across all switch directions.

2. Hindi dominant bilinguals would be slower on English to Hindi (backward) switch direction in comparison to Hindi to English (forward) switch direction.

3. Balanced bilinguals would not differ in terms of response time required in Hindi to English (forward) and English to Hindi (backward) switch direction.

\section{METHOD}

\section{Participants:}

Thirty-three right-handed bilinguals (16 Hindi dominant bilinguals and 17 balanced bilinguals) with age range of 22 to 28 years (Mean $=23.61, \mathrm{SD}= \pm 2.28$ ) participated in the study. All the participants were native Hindi speakers and acquired English as their second language. The participants had normal or corrected to normal vision and did not suffer from any medical condition. All the participants were subject to Voice Detection test and only those who passed the test were included in the study.

\section{Design:}

A 2 (Language Dominance: Hindi dominant, \& balanced bilinguals) x 4 (Language switching: Hindi to Hindi, English to English, Hindi to English, \& English to Hindi) mixed factorial design with repeated measures on the last factor was employed.

Independent variables: Language dominance and Language switching. Language Dominance is operationally defined as the ease and confidence with a particular language. In this study, it is determined by the Language Self-Evaluation Scale (LSES). The rating scale provides a composite output of their preferred language, confidence in a particular language, self-rated proficiency, and frequency of usage in each of their language. Language switching is operationally defined in terms of direction of the switch. In the present study the participants were subject to, a task induced transition. This transition could either be in Hindi to Hindi, English to English, forward (Hindi to English) or backward (English to Hindi).

Dependent variable: Response latency.

Response latency is defined in terms of time required to respond after the presentation of the stimulus. In the present study, it was measured with the help of Superlab Cedrus voice key. As the participant utters the response, the voice key was triggered, and the Voice-onset Reaction Time (VoRT) was recorded and retained. Errors in responding (like, incorrect naming, incorrect use of language while naming, etc.) was noted down manually by the experimenter and such data points were excluded from the final analysis. 


\section{Effect of Language Switching On the Response Latency in the Cued Picture-Naming Paradigm among Hindi Dominant and Balanced Bilinguals}

\section{Task description:}

Cued Picture-naming task was used to examine the cognitive cost associated with language switching. The task was developed using Superlab Software version 4.0. Cedrus voice key was used to record the reaction time of the participants. The audio file of the responses was also maintained using an external microphone in order to later check the accuracy of the response. The stimulus involved ten line drawings (selected from Snodgrass and Vanderwart, 1980), which were to be named by the participants on the basis of the language cues. In the task, a single trial constituted of a fixation (+), then the language cue, which could be either बोलो or say which was followed by the presentation of a line drawing. The participant was required to name the picture as soon as it was flashed over the computer screen. When the word 'बोलो' was flashed the participant was required to name the line drawing in Hindi language while when the word 'say' was flashed the participant was required to name the picture in English language. The picture disappeared from the computer screen as soon as the participant responded to it. After the subject responded to the picture, a blank screen was flashed over the computer screen. The whole experiment involved 600 trials. The participants were provided short rest pause of five seconds after every 20th trial and a rest pause of thirty seconds after every 200th trial. The entire experimental process required about 30 to 35 minutes.

\section{The Pictorial description of the task is depicted below:}

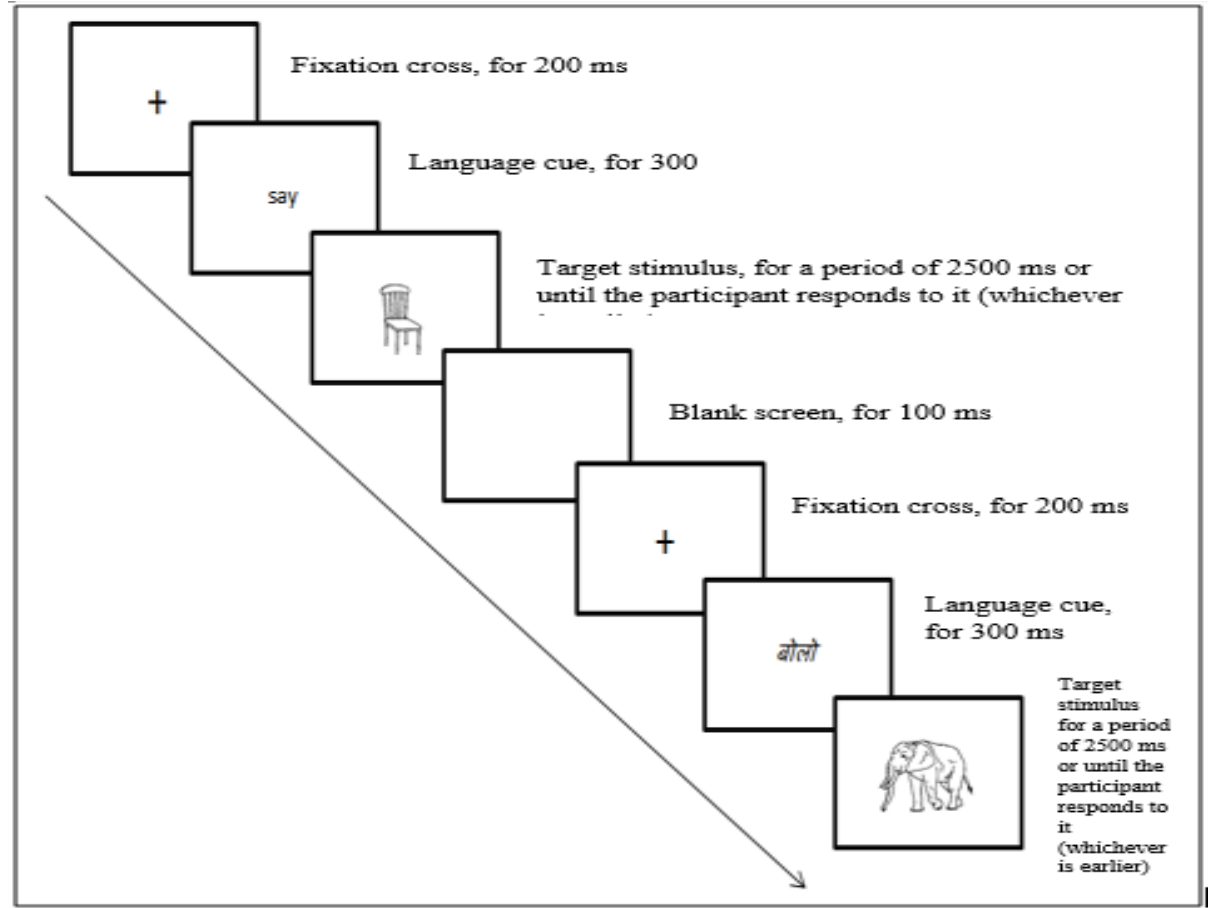

The response time from all the participants was entered into SPSS version 16 (at Department of Psychology, Banaras Hindu University) and then analyzed in order to test the assumptions of two way mixed ANOVA. The result indicated that, there were no outliers in the data, as assessed by inspection of a boxplot. Response latency was normally distributed for all language switches at 


\section{Effect of Language Switching On the Response Latency in the Cued Picture-Naming Paradigm among Hindi Dominant and Balanced Bilinguals}

all language dominance levels, as assessed by Shapiro-Wilk's test $(\mathrm{p}>.05)$. There was homogeneity of variances, as assessed by Levene's test of homogeneity of variance ( $p>.05)$. There was homogeneity of covariances, as assessed by Box's test of equality of covariance matrices $(\mathrm{p}=.499)$. Mauchly's test of sphericity indicated that the assumption of sphericity was violated for the two-way interaction, $\chi 2$ Epsilon for Greenhouse-Geisser estimate of sphericity was .785 which is greater than 0.75 . Therefore, degree of freedom was corrected using HuynhFeldt.

Mean scores and standard deviation were calculated for the performance measure which is presented in Table 1 and graphically displayed in Figure 1. Results revealed that, balanced bilinguals were faster in comparison to Hindi dominant bilinguals across all switch directions. For Hindi stay condition, balanced bilinguals required Mean response time of $771.483 \mathrm{~ms}$ (SD = \pm 103.633 ) while Hindi dominant bilinguals required Mean response time of $804.456 \mathrm{~ms}$ (SD = \pm 115.013 ). In English stay condition, balanced bilinguals required Mean response time of $784.968 \mathrm{~ms}(\mathrm{SD}= \pm 115.964)$ while Hindi dominant bilinguals required Mean response time of $894.271 \mathrm{~ms}$ ( $\mathrm{SD}= \pm 110.281$ ). In the English to Hindi (backward) switch condition, balanced bilinguals required a mean response time of $933.156 \mathrm{~ms}, \mathrm{SD}= \pm 136.409$ ) while Hindi dominant bilinguals required a Mean response time of $1116.350 \mathrm{~ms}(\mathrm{SD}= \pm 153.798)$ In Hindi to English (forward) switch condition balanced bilinguals required mean response time of $956.404 \mathrm{~ms}$ (SD $= \pm 139.389$ ) while Hindi dominant bilinguals required Mean response time of $993.136 \mathrm{~ms}$ (SD = $\pm 179.112)$.

The results also indicate that Hindi dominant bilinguals were faster in Hindi to English (forward) switch condition ( $\mathrm{M}=993.136, \mathrm{SD}= \pm 179.112)$ in comparison to English to Hindi (backward) switch condition $(\mathrm{M}=1116.350, \mathrm{SD}= \pm 153.798)$. While there balanced bilinguals required almost equal response time in Hindi to English (forward) switch condition (M=956.404, SD= $\pm 139.389)$ and English to Hindi (backward) switch condition $(\mathrm{M}=933.156, \mathrm{SD}= \pm 136.409)$.

To examine the main and interaction effects the obtained data were subjected to analysis of variance (ANOVA). A 2 (Language dominance: Hindi dominant bilinguals and balanced bilinguals) x 4 (Language switching: Hindi to Hindi, English to English, Hindi to English and English to Hindi) mixed factorial analysis of variance. The language dominance was treated as between-subjects factor and the language switching was treated as a within- subjects factor. There was a statistically significant interaction between the language switching and language dominance on response time in reading task, $\mathrm{F}(2.643,81.936)=13.132, \mathrm{p}<.0005$, partial $\eta 2=$ $.298, \varepsilon=.785$. 
Effect of Language Switching On the Response Latency in the Cued Picture-Naming Paradigm among Hindi Dominant and Balanced Bilinguals

Table 1: Mean reaction time scores as a function of language dominance and language switching

\begin{tabular}{|c|c|c|c|c|}
\hline \multirow[t]{3}{*}{ Language switching } & \multicolumn{4}{|c|}{ Language dominance } \\
\hline & \multicolumn{2}{|c|}{$\begin{array}{l}\text { Hindi dominant bilinguals } \\
\qquad(\mathrm{N}=16)\end{array}$} & \multicolumn{2}{|c|}{$\begin{array}{l}\text { Balanced bilinguals } \\
\qquad(\mathrm{N}=17)\end{array}$} \\
\hline & Mean & SD & Mean & SD \\
\hline Hindi to Hindi & 804.456 & \pm 115.013 & 771.483 & \pm 103.633 \\
\hline English to English & 894.271 & \pm 110.281 & 784.968 & \pm 115.964 \\
\hline English to Hindi & 1116.350 & \pm 153.798 & 933.156 & \pm 136.409 \\
\hline Hindi to English & 993.136 & \pm 179.112 & 956.404 & \pm 139.389 \\
\hline
\end{tabular}

Table 2: Summary of $3 \times 4$ analysis of variance in the measure of response latency

\begin{tabular}{|c|c|c|c|c|c|c|}
\hline Source of Variance & $\begin{array}{c}\text { Sum of } \\
\text { squares }\end{array}$ & df & $\begin{array}{c}\text { Mean } \\
\text { squares }\end{array}$ & $\mathbf{F}$ & $\boldsymbol{p}$ & $\begin{array}{c}\text { Partial } \\
\boldsymbol{\eta} \mathbf{2}\end{array}$ \\
\hline $\begin{array}{c}\text { A: Between subjects } \\
\text { (Language } \\
\text { dominance) }\end{array}$ & 270331.427 & 1 & 270331.427 & 4.370 & .045 & .124 \\
\hline $\begin{array}{c}\text { B: Within Subjects } \\
\text { (Language } \\
\text { switching) }\end{array}$ & 1225375.966 & 2.643 & 463610.957 & 128.893 & .000 & .806 \\
\hline A X B & 124839.946 & 2.643 & 47232.171 & 13.132 & .000 & .298 \\
\hline Error & 294714.066 & 81.936 & 3596.860 & & & \\
\hline
\end{tabular}

Figure 1:Response latency as a function of language dominance and switching
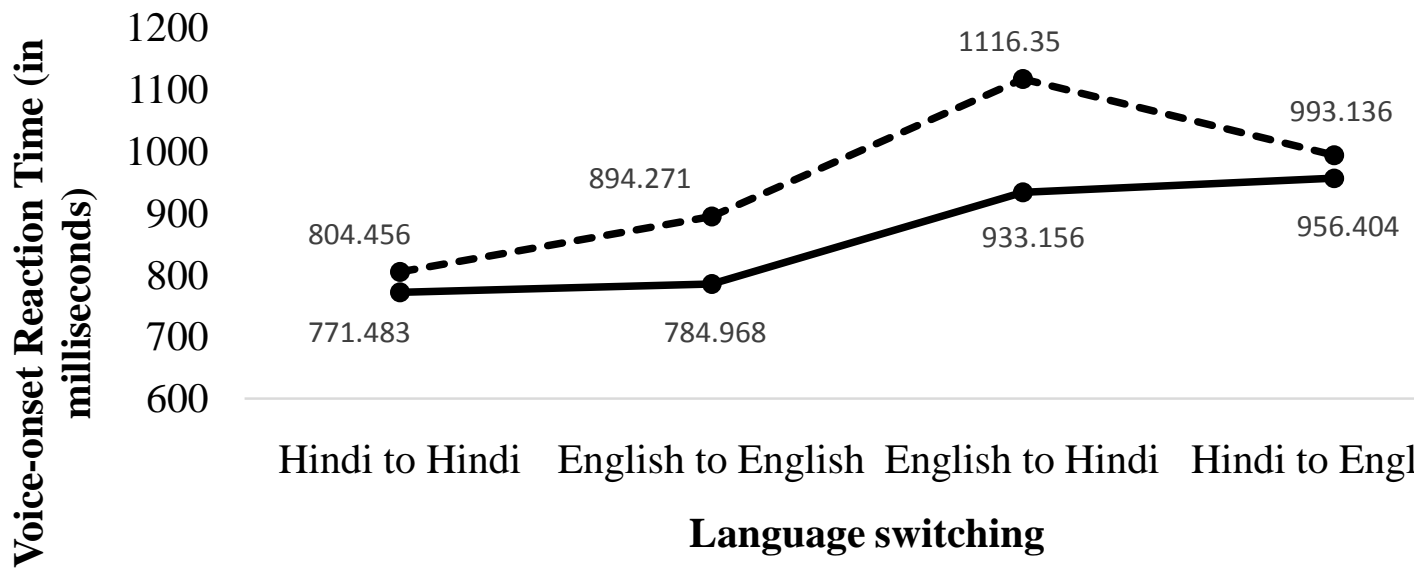

Hindi to Hindi English to English English to Hindi Hindi to English Language switching

- - Hindi dominant bilinguals $\rightarrow$ Balanced bilinguals 
Effect of Language Switching On the Response Latency in the Cued Picture-Naming Paradigm among Hindi Dominant and Balanced Bilinguals

Table 3:Showing within-subjects effect across different language dominance conditions

\begin{tabular}{|c|c|c|c|c|c|c|c|}
\hline \multicolumn{2}{|c|}{ Source } & \multirow{2}{*}{$\begin{array}{c}\begin{array}{c}\text { Sum of } \\
\text { squares }\end{array} \\
860879.058\end{array}$} & \multirow{2}{*}{\begin{tabular}{|c|} 
df \\
1.792 \\
\end{tabular}} & \multirow{2}{*}{$\begin{array}{c}\text { Mean } \\
\text { square } \\
480481.232\end{array}$} & \multirow{3}{*}{$\begin{array}{c}\mathbf{F} \\
70.035\end{array}$} & \multirow{3}{*}{$\begin{array}{c}p \\
.000\end{array}$} & \multirow{3}{*}{$\begin{array}{l}2 \\
.824\end{array}$} \\
\hline \multirow[t]{2}{*}{$\begin{array}{c}\text { Hindi dominant } \\
\text { bilinguals }\end{array}$} & $\begin{array}{l}\text { Language } \\
\text { switching }\end{array}$ & & & & & & \\
\hline & Error & 184382.371 & 26.876 & 6860.605 & & & \\
\hline \multirow[t]{2}{*}{$\begin{array}{l}\text { Balanced } \\
\text { bilinguals }\end{array}$} & $\begin{array}{l}\text { Language } \\
\text { switching }\end{array}$ & 477726.161 & 3 & 159242.054 & \multirow[t]{2}{*}{69.279} & \multirow[t]{2}{*}{.000} & \multirow[t]{2}{*}{.812} \\
\hline & Error & 110331.695 & 48 & 2298.577 & & & \\
\hline
\end{tabular}

There was a statistically significant effect of language switching on speed of response for the Hindi dominant bilingual group, $F(1.792,26.876)=70.035, p<.001$, partial $\eta 2=.824 \varepsilon=.597$, and for the balanced bilingual group, $F(3,48)=69.279, \mathrm{p}<.001$, partial $\eta 2=.812$.Pair-wise comparison revealed that for the Hindi dominant bilingual group, difference in response latency was statistically significantly reduced at English to Hindi and Hindi to English switch conditions $(M=123.214, S E=24.243, p=.000)$. While for the balanced bilingual group, response latency was not statistically significantly different between Hindi to English and English to Hindi switching conditions $(\mathrm{M}=23.248, \mathrm{SE}=17.658, \mathrm{p}=.207)$.

Figure 2: Response latency in forward and backward switching as a function of Language dominance

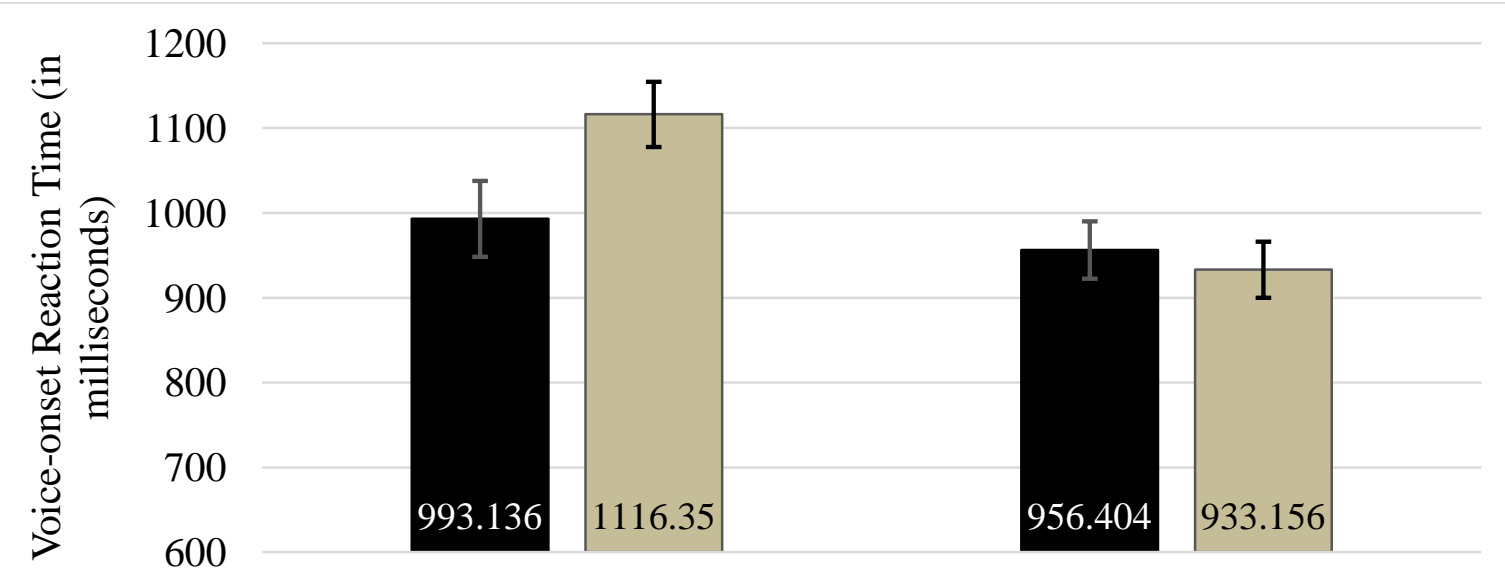

Hindi dominant bilinguals Balanced bilinguals

- Hindi to English (forward) switching

$\square$ English to Hindi (backward) switching 


\section{DISCUSSION}

Aim of the present study was to examine the effect of language switching on the response latency in the cued picture-naming paradigm among Hindi dominant and balanced bilinguals. We can find that the interaction effect of language dominance and switching was also found significant. The main effects of language dominance and language switching are also significant.

Based on these results, our hypothesis that 'Balanced bilinguals would be faster than Hindi dominant bilinguals across all switch directions' is confirmed. Balanced bilingualism has been regarded as an asset, as it facilitates many other executive functioning. Balanced bilinguals are automatically trained in executive control skills, such as inhibiting responses which compete and task switching. Since balanced bilinguals are better than unbalanced bilinguals on task switching (e.g., Yow \& Li, 2015), this result can be used as a supporting evidence to our findings. Evidences from several neuroimaging studies also depict that the cortical areas which are essential for general executive functioning, for example, dorsolateral prefrontal cortex, left middle temporal gyrus, left inferior frontal gyrus, and anterior cingulated cortex, also mediate language processing and bilingual language switching (e.g., Hernández, Martinez, and Kohnert 2000; Abutalebi and Green, 2008; Toro, Fox \& Paus, 2008; Hedden and Gabrieli, 2010; RubioFernández and Glucksberg, 2012).

The findings of our study also confirm the second hypothesis that 'Hindi dominant bilinguals would be slower on English to Hindi (backward) switch direction in comparison to Hindi to English (forward) switch direction'. This finding is in alignment with the views of the Inhibitory control model that 'Inhibition is reactive' which shows that the strength of inhibition is contingent upon the strength of activation of a particular language. Hindi being the dominant language for this group, it would be more difficult to move back to Hindi from English (e.g., Green, 1998; Meuter \& Allport, 1999; \& Macizo, Bajo \& Paolieri, 2012). Thus Hindi dominant bilinguals would be slower when switching to the Hindi language and that there is asymmetry in the switch cost with more response time required in backward switching in comparison to forward switching.

The mean difference between backward and forward switching in balanced bilinguals was not found significant (e.g., Costa \& Santesteban, 2004; Costa, Santesteban\& Ivanova, 2006; \& Gollan \& Ferreira, 2009) On the basis of the result can speculate that, since balanced bilinguals are equally dominant in both the languages the competition between the languages must not be as hard to resolve as in the case of Hindi dominant bilinguals. And that for balanced bilinguals, both the languages almost required equal strength in order to be inhibited, thus we obtain symmetry in the time required to switch forward or backward. This finding again implicates that switching between the two languages for a balanced bilingual often costs less in terms of cognitive resources and that balanced bilingualism acts as an asset in this way. 


\section{Effect of Language Switching On the Response Latency in the Cued Picture-Naming Paradigm among Hindi Dominant and Balanced Bilinguals}

In the light of results, we can conclude that language dominance does play a crucial role in the context of response time associated with language switching. And that balanced bilinguals are at a better stand as their overall response time is lower than that of unbalanced bilinguals and that there is symmetrical switch cost associated with switching from one language to another.

\section{REFERENCES}

Abutalebi, J., \& Green, D. W. (2008). Control mechanisms in bilingual language production: neural evidence from languages witching studies. Language and Cognitive Processes, 23,557-582.

Colzato, L.S., Bajo, M.T., van den Wildenberg, W., Paolieri, D., Nieuwenhuis, S., Heij, W. L., \& Hommel, B. (2008). How does bilingualism improve executive control? A comparison of active and reactive mechanisms. Journal of Experimental Psychology: Learning, Memory and Cognition, 34(2), 302-312.

Costa, A., \& Santesteban, M. (2004). Lexical access in bilingual speech production: Evidence from language switching in highly proficient bilinguals and L2 learners. Journal of Memory and Language, 50, 491-511.

Costa, A., Santesteban, M., \& Ivanova, I. (2006). How do highly proficient bilinguals control their lexicalization process? Inhibitory and language-specific selection mechanisms are both functional. Journal of Experimental Psychology: Learning, Memory and Cognition, 32, 1057-1074.

French, R. M. \& Jacquet, M. (2004). Understanding bilingual memory: models and data. Trends in Cognitive Sciences, 8(2), 87-93.

Gollan, T. H., \& Ferreira, V. S. (2009). Should I stay or should I switch? A cost benefit analysis of voluntary language switching in young and aging bilinguals. Journal of Experimental Psychology: Learning, Memory, and Cognition, 35, 640-665.

Green, D. W. (1998). Mental control of the bilingual lexico-semantic system. Bilingualism: Language and Cognition, 1, 67-81.

Hedden, T., \&Gabrieli, J. D. E. (2010). Shared and selective neural correlates of inhibition, facilitation, and shifting processes during executive control. Neuroimage, 51,421-431.

Hernandez, A. E., Dapretto, M., Mazziotta, J., \& Bookheimer, S. (2001). Language switching and language representation in Spanish-English bilinguals: an fMRI study. NeuroImage, 14, 510-520.

Hernández, A. E., Martinez, A., \& Kohnert, K. (2000). In search of the language switch: an fMRI study of picture naming in Spanish-English bilinguals. Brain and Language, 73,421-431.

Macizo, P., Bajo, T., \& Paolieri, D. (2012). Language switching and language competition. Second Language Research, 28, 131-149.

Macnamara, J. (1967). The bilingual's linguistic performance- A psychological overview. Journal of Social Issues, 23(2), 58-77. 
Meuter, R. (2005). Language selection in bilinguals: Mechanisms and processes. In J. Kroll \& A. De Groot (Eds.), Handbook of bilingualism: Psycholinguistic approaches (pp. 349-370). New York, NY: Oxford University Press.

Meuter, R., \& Allport, A. (1999). Bilingual language switching in naming: Asymmetrical costs of language selection. Journal of Memory and Language, 40, 25-40.

Rubio-Fernández, P., and Glucksberg, S. (2012). Reasoning about other people’s beliefs: bilinguals have an advantage. Journal of Experimental Psychology: Learning, Memory and Cognition, 38, 211-217.

Snodgrass, J. G., \& Vanderwart, M. (1980). A standardized set of 260 pictures: norms for name agreement, image agreement, familiarity, and visual complexity. Journal of Experimental Psychology: Human Learning and Memory, 6 (2), 174-215.

Thomas, M. S. C., \& Allport, A. (2000). Language switching costs in bilingual visual word recognition. Journal of Memory and Language, 43(1), 44-66.

Toro, R., Fox, P. T., \& Paus, T. (2008). Functional coactivation map of the human brain. Cerebral Cortex, 18,2553-2559.

Yow, W.Q., \& Li, X. (2015). Balanced bilingualism and early age of second language acquisition as the underlying mechanisms of a bilingual executive control advantage: why variations in bilingual experiences matter. Frontiers in Psychology, 6, 1-12.

How to cite this article: K Mishra, H Asthana, I Singh (2016), Effect of Language Switching On the Response Latency in the Cued Picture-Naming Paradigm among Hindi Dominant and Balanced Bilinguals, International Journal of Indian Psychology, Volume 3, Issue 3, No. 9, DIP: 18.01.168/20160303, ISBN: 978-1-365-13820-1 